\title{
BMJ Open Prevalence of anxiety and depressive symptoms among emergency physicians in Libya after civil war: a cross- sectional study
} Muhammed Elhadi (D) , ${ }^{1}$ Ala Khaled, ${ }^{1}$ Ans Bassam Malek, ${ }^{2}$
Ahmed El-Alem El-Azhari, ${ }^{3}$ Ahmed Zakaria Gwea, ${ }^{3}$ Ahmed Zaid, ${ }^{1}$
Salman Mabruk Elturki, ${ }^{4}$ Ahmed Aburgegah, ${ }^{2}$ Munir Ahmed K Abu Ageila, ${ }^{5}$
Abdulmueti Alhadi, ${ }^{6}$ Hafed Abdulwahhab Albashkar, ${ }^{7}$ Aliyah Mustafa Alshareef, ${ }^{8}$
Adel Basher Ben Nama, ${ }^{9}$ Nizar Aljarboue Mohammed Sahboun, ${ }^{7}$ Hazem Ahmed ${ }^{1}$
To cite: Elhadi M, Khaled A, Malek AB, et al. Prevalence of anxiety and depressive symptoms among emergency physicians in Libya after civil war: a crosssectional study. BMJ Open 2020;10:e039382. doi:10.1136/ bmjopen-2020-039382

- Prepublication history for this paper is available online. To view these files, please visit the journal online (http://dx.doi. org/10.1136/bmjopen-2020039382).

Received 15 April 2020 Revised 25 June 2020 Accepted 16 July 2020

\section{Check for updates}

(c) Author(s) (or their employer(s)) 2020. Re-use permitted under CC BY-NC. No commercial re-use. See rights and permissions. Published by BMJ.

For numbered affiliations see end of article.

\section{Correspondence to} Dr Muhammed Elhadi; muhammed.elhadi.uot@gmail. com

\section{ABSTRACT}

Objectives We aimed to identify the prevalence of depression and anxiety among physicians working in the emergency departments of nine tertiary care centres in Libya.

Design This was a cross-sectional study.

Setting Nine main tertiary centres in Libya

Participants Emergency department doctors were surveyed between December 2018 and February 2019. Intervention The standardised Hospital Anxiety and Depression Scale (HADS) was selected as a measurement tool for analysing anxiety and depression symptoms; a HADS score of 8 indicated anxiety as well as depression symptoms. The primary outcomes were anxiety and depression, which were tabulated with independent sociodemographic variables. $\chi^{2}$ tests were conducted to compare the prevalence of anxiety and depression between the groups. Statistical analysis was performed using SPSS V. 25.

Results A total of 108 out of 150 (72\%) emergency physicians from all levels participated in the study and took the survey. The emergency physicians had a mean \pm SD age of $31.2 \pm 4.5$ years, and were predominantly males (74 out of $108,68.5 \%)$. Overall, 49 (45.4\%) physicians reached the cutoff score to define both depression and anxiety (ie, a score 28). In terms of violence, $71(65.7 \%)$ reported incidents of verbal violence, while 26 (24.1\%) reported physical violence or abuse by militias. In addition, 28 reported being threatened by militias.

Conclusion The high prevalence rate of anxiety and depression is of concern, and the high rate of physical and verbal abuse highlights the range of abuse endured by doctors in Libya. Therefore, screening for anxiety and depression at regular intervals is needed to avoid the deterioration of mental health, which can increase the risk of suicide and dropping out, and decrease the level of healthcare for patients.

\section{INTRODUCTION}

Depression and anxiety symptoms are highly prevalent among physicians, especially those working in hospital emergency departments where they operate under stressful conditions

\section{Strengths and limitations of this study}

- This is the first study to survey a representative sample of emergency doctors from nine hospitals in Libya after the civil war, and assess their mental health status.

- The study sample excluded participants with possible confounding effects and was based on adequate inclusion criteria.

- The study assessed the prevalence of violence and verbal abuse among physicians who worked in Libya during the civil war.

- Due to the cross-sectional study design, a causal relationship cannot be inferred from the data, which necessitates future prospective studies.

- Stigmatisation for having a mental illness may affect physicians' willingness to declare their mental status.

due to their job circumstances in terms of working hours, number of night shifts and social pressures. ${ }^{12}$ In addition, Libyan physicians are at higher risk of being kidnapped, killed, or threatened by militias or armed forces due to the local circumstances of the civil war. ${ }^{3}$

Despite knowledge about stressors and health hazards, physicians may not be aware of the factors that can affect their mental health. However, identifying the symptoms of anxiety and depression is crucial, so that appropriate interventions can be applied. Burnout and depressive disorders have increased among physicians due to multiple environmental and personal factors, such as lack of social support, significant mental and physical demands, and lack of job satisfaction. ${ }^{4}$

Several studies have identified a link between decreased quality of patient care 
associated with distress and increased medical error rates in clinical residents. ${ }^{5-7}$ However, the prevalence of anxiety and depression symptoms varies across studies, with some reporting more than half of all participating physicians as depressed. ${ }^{8}$ Studies also indicate different results depending on the years of training, medical speciality and demographic characteristics. ${ }^{9-11}$

Although many studies have focussed on physician anxiety and depression symptoms and have identified a substantial association, questions regarding risk factors of physicians' anxiety and depression remain, especially in conflict areas where physicians are at a higher risk of mental illness. ${ }^{12} 13$

Not enough data are available regarding anxiety and depression rates among doctors or the general population in Libya, following multiple civil wars. ${ }^{14}$ In addition, significant issues have arisen around the attrition rate of doctors working in Libyan emergency departments due to conflicts and insecurity since $2011 .^{1516}$ Circumstances have led to an increased risk of verbal and physical violence against doctors who work in emergency departments to improve the life-threatening conditions imposed by militias that control the cities in Libya. ${ }^{17}$

The estimation of depression and anxiety prevalence among emergency physicians is essential for helping health authorities to identify factors contributing to physician distress and promote mitigation in this vulnerable population. Therefore, in this study, we aimed to determine the prevalence of depression and anxiety among emergency department doctors in Libya.

\section{METHODS}

\section{Study design and interventions}

\section{Participants}

The study participants were emergency doctors serving in Libyan hospitals for at least 3 months. Written consent was obtained before the completion of the survey. Participants with a history of mental health disorders and comorbidities, such as chronic pain, hypertension and diabetes, were excluded. One hundred and fifty emergency department staff who met the criteria were asked to complete an anonymous three-page survey. The participants were approached by the authors by visiting the emergency departments of the hospitals during their shifts. The authors undertook a paper-based questionnaire that contained a participant information sheet along with a study measurement tool, and they asked the participants questions related to the inclusion and exclusion criteria before participating in the study to ensure that they met the criteria of the study. Those who did not return the questionnaire or declined to fill in and respond to the questionnaire were not included in the analysis.

\section{Protocol}

This cross-sectional survey was conducted between December 2018 and February 2019, in nine main tertiary hospitals with emergency departments in Libya. It is estimated that approximately 300 physicians work in the emergency departments of these Libyan hospitals.

\section{Measurements}

Information regarding years of experience, exercise regimen and smoking history was recorded. In addition, data on verbal and physical abuse were documented. The standardised Hospital Anxiety and Depression Score (HADS) inventory was selected as a measurement tool for analysing the symptoms of anxiety and depression. ${ }^{18} 19$ HADS is a screening tool with seven items to evaluate each condition. Each item is scored on a 4-point Likert scale of 0 to 3 , resulting in a total range of 0 to 21 points. A score of $\leq 7$ is considered as 'normal', 8 to 10 as 'mild', 11 to 14 as 'moderate', and 15 to 21 as 'severe' for both the anxiety and depression screenings. A score of $\geq 8$ is considered a 'case' for either condition. ${ }^{2021}$ The HADS scale has a high level of internal consistency, as designated by a Cronbach's alpha of 0.83 for the anxiety subscale and 0.82 for the depression subscale. ${ }^{19}$ All participants provided consent prior to participating in the study.

\section{Statistical analysis}

Anxiety and depression were the main parameters observed in this study, which were tabulated with independent variables. $\chi^{2}$ tests were conducted to compare the prevalence of anxiety and depression between the groups. Logistic regression analysis was used to analyse the risk factors for anxiety and depression symptoms. Adjusted ORs and 95\% CIs were calculated for variables. Results with $p$ values less than 0.05 were considered statistically significant. The data were analysed using IBM SPSS Statistics V.25 software.

\section{Participants and public involvement}

No participants were involved in establishing the research question, planning or performing the statistical analyses. No participants were invited to offer guidance on presenting the findings or writing the results. There are no proposals or plans to disseminate the study findings to the study participants.

\section{Ethical considerations}

All participants provided consent prior to participating in the study without identified data.

\section{RESULTS}

During the study period, between December 2018 and February 2019, 108 out of $150(72 \%)$ emergency physicians from all levels answered the survey and participated in the study. They had a mean \pm SD age of $31.2 \pm 4.5$ years, and were predominantly male (74 out of $108(68.5 \%)$ ). In addition, $73(67.6 \%)$ of the physicians were from Tripoli, and the remaining $35(32.4 \%)$ were from other cities. Almost half of them were married (52 out of 108 $(48.1 \%))$ and $56(51.9 \%)$ were single (table 1$)$.

The participants had a mean experience of $3.32 \pm 3.1$ years in emergency departments; $62(63 \%)$ worked one 
24 hours shift per week, while the other 38 (35\%) worked one 12 hours night or day shift per week.

Overall, 49 (45.4\%) physicians reached the cut-off score, indicating a high likelihood of clinically significant depressive symptoms $(\geq 8)$, and $49(45.4 \%)$ achieved a cut-off score, indicating symptoms of anxiety. The mean anxiety score was $7.2 \pm 3.03$, with a maximum of 16 , while the mean score for depression was $7.3 \pm 2.75$, with a maximum of 14 . Table 2 indicates the grade of anxiety and depression among the study participants.

Among all participants, $49(45.4 \%)$ had both anxiety and depression. There was only one case of severe anxiety, and no cases of severe depression were recorded. Tables 3 and 4 illustrate the associations between demographic and personal characteristics, and the occurrence of anxiety and/or depression.

In terms of violence, $71(65.7 \%)$ physicians reported verbal violence, while $26(24.1 \%)$ reported physical violence or abuse by militias. There was a significant relationship between anxiety and depression scores $(p<0.001)$ and violence.

There were no significant impact of gender $(p=0.553)$, physical exercise $(\mathrm{p}=0.713)$ or age $(\mathrm{p}=0.089)$ on symptoms of depression. The impact of service years on depression score was significant $(p<0.05)$, with fewer years of experience resulting in a higher prevalence of depression. In addition, smoking was associated with a lower rate of depression $(\mathrm{p}<0.05)$. Being threatened, and verbally and physically abused were all associated with a higher

\begin{tabular}{|c|c|}
\hline Characteristics & All participants $(n=108)$ \\
\hline Age, median (IQR) (years) & 30.0 (28.0 to 33.0$)$ \\
\hline Male n(\%) & $74(68.5)$ \\
\hline \multicolumn{2}{|l|}{ Marital status n (\%) } \\
\hline Single & $56(51.9)$ \\
\hline Married & $52(48.1)$ \\
\hline Working in other hospitals $\mathrm{n}(\%)$ & $44(40.7)$ \\
\hline Years of experience, mean $\pm S D$ & $3.32 \pm 3.1$ \\
\hline Physical exercise n (\%) & $29(26.9)$ \\
\hline Intent to continue in EM & $41(38.0)$ \\
\hline \multicolumn{2}{|l|}{ Work shift per week n (\%) } \\
\hline 12 hours day shift & $25(23.1)$ \\
\hline 12 hours night shift & $13(12)$ \\
\hline 24 hours & $68(63)$ \\
\hline None & $2(1.9)$ \\
\hline Smoking n (\%) & $31(28.7)$ \\
\hline Verbal abuse n (\%) & $71(65.7)$ \\
\hline Physical abuse n (\%) & $26(24.1)$ \\
\hline Threatening n (\%) & $28(25.9)$ \\
\hline
\end{tabular}

EM, emergency medicine.
Table 2 Grade of anxiety and depression in study participants based on the HADS inventory $(n=108)$

\begin{tabular}{llll}
\hline Category & Grade & Frequency & Per cent \\
\hline Anxiety & Normal & 59 & 54.6 \\
& Mild & 33 & 30.6 \\
& Moderate & 15 & 13.9 \\
& Severe & 1 & 0.9 \\
Depression & Normal & 59 & 54.6 \\
& Mild & 36 & 33.3 \\
& Moderate & 13 & 12 \\
& Severe & 0 & 0 \\
\hline
\end{tabular}

HADS, Hospital Anxiety and Depression Scale.

prevalence of depression. However, the impact of these characteristics was not significant $(\mathrm{p}>0.05)$.

Regarding anxiety, there were no significant impact of gender $(\mathrm{p}=0.553)$, age $(\mathrm{p}=0.093)$, physical exercise

Table 3 Baseline characteristics and their associations with anxiety score $\geq 8$

\begin{tabular}{|c|c|c|c|}
\hline Characteristics & $\begin{array}{l}\text { HADS-A } \\
\text { score }<8\end{array}$ & $\begin{array}{l}\text { HADS-A } \\
\text { score } \geq 8\end{array}$ & $P$ value \\
\hline n (\%) & $59(54.6)$ & $49(45.4)$ & \\
\hline Age, mean $\pm S D$ & $31.54 \pm 4.76$ & $30.62 \pm 4$ & 0.093 \\
\hline Gender & & & 0.553 \\
\hline Male & 39 & 35 & \\
\hline Female & 20 & 40 & \\
\hline Marital status & & & 0.538 \\
\hline Single & 29 & 27 & \\
\hline Married & 30 & 22 & \\
\hline $\begin{array}{l}\text { Working in other } \\
\text { hospitals }\end{array}$ & 27 & 17 & 0.244 \\
\hline Years of experience & & & 0.780 \\
\hline$\leq 3$ years & 37 & 32 & \\
\hline$>3$ years & 22 & 17 & \\
\hline Physical exercise & 16 & 13 & 0.945 \\
\hline Intent to continue in EM & 23 & 18 & 0.811 \\
\hline Work shift per week & & & 0.569 \\
\hline 12 hours day shift & 15 & 10 & \\
\hline 12 hours night shift & 9 & 4 & \\
\hline 24 hours & 34 & 34 & \\
\hline None & 1 & 1 & \\
\hline Smoking & 14 & 17 & 0.210 \\
\hline Verbal abuse & 35 & 36 & 0.231 \\
\hline Physical abuse & 11 & 15 & 0.194 \\
\hline Threatening & 11 & 17 & 0.092 \\
\hline
\end{tabular}

EM, emergency medicine; HADS, Hospital Anxiety and Depression Scale. 


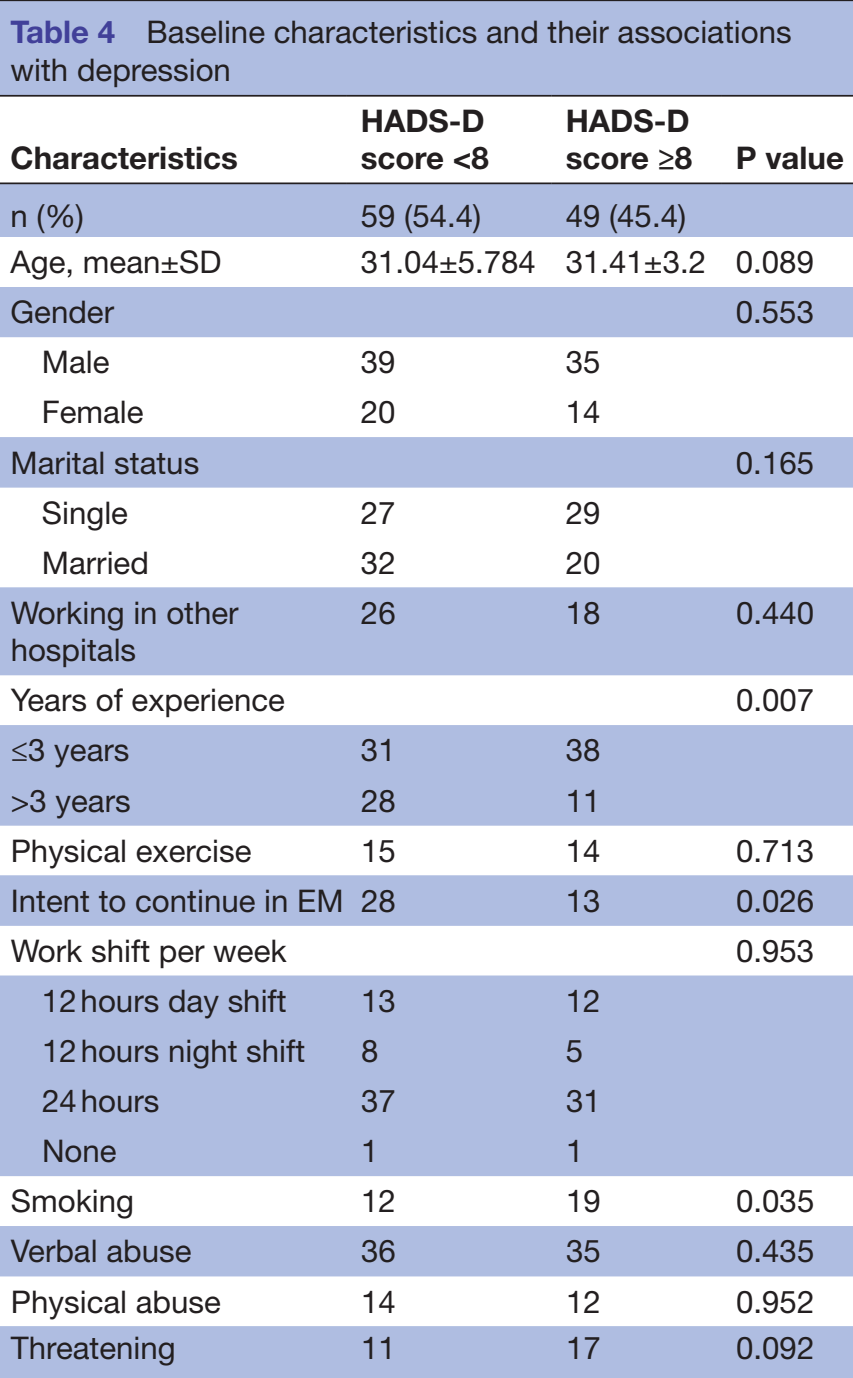

EM, emergency medicine; HADS, Hospital Anxiety and Depression Scale.

$(\mathrm{p}=0.945)$, service years $(\mathrm{p}=0.78)$ or smoking $(\mathrm{p}=0.21)$. Furthermore, being threatened, and verbally and physically abused were not significantly associated with anxiety ( $>0.05)$. Working the night shift was not statistically associated with symptoms of depression or anxiety $(p>0.05)$.

Logistic regression was performed to ascertain the effects of age, gender, verbal and physical abuse, and threatening, and the likelihood that participants had depression and/or anxiety due to these factors. For depression, the model disclosed the following variables: age $(\mathrm{OR}=0.968,95 \%$ CI: 0.884 to $1.061, \mathrm{p}>0.05)$, female gender $(\mathrm{OR}=0.861,95 \% \mathrm{CI}$ : 0.339 to $2.184, \mathrm{p}>0.05)$, verbal abuse ( $\mathrm{OR}=1.105,95 \% \mathrm{CI}: 0.447$ to $2.734, \mathrm{p}>0.05)$, physical abuse (OR=0.413, 95\% CI: 0.118 to 1.452 , $\mathrm{p}>0.05$ ) and threatening ( $\mathrm{OR}=4.126,95 \% \mathrm{CI}: 1.117$ to $15.235, \mathrm{p}<0.05)$. For anxiety, the model disclosed the following variables: age $(\mathrm{OR}=1.104,95 \% \mathrm{CI}: 0.987$ to 1.236 , $\mathrm{p}>0.05)$, female gender $(\mathrm{OR}=0.886,95 \%$ CI: 0.350 to $2.239, \mathrm{p}>0.05)$, verbal abuse $(\mathrm{OR}=1.423,95 \% \mathrm{CI}: 0.562$ to $3.602, \mathrm{p}<0.05)$, physical abuse $(\mathrm{OR}=1.065,95 \% \mathrm{CI}$ :
0.339 to $3.348, \mathrm{p}>0.05)$ and threatening $(\mathrm{OR}=1.532$, $95 \%$ CI: 0.473 to $4.957, \mathrm{p}<0.05)$.

\section{DISCUSSION}

We believe that civil war played a major role in increasing the rate of depression and anxiety among emergency medicine doctors working in Libya. This study, surveyed 108 emergency physicians from different hospitals in Libya for a specific period of their careers. We demonstrated that $45.4 \%$ of participants had a high likelihood of depression and anxiety. Higher scores on the respective anxiety and depression scales were associated with several risk factors, but they did not reflect statistically significant results. Moreover, this study unveils a very concerning issue regarding threatening, and verbal and physical abuse rates against doctors. The prevalence of such behaviour is an alarming sign for authorities and the broader society in Libya. Multiple civil wars have damaged central power systems and have increased militia control.

This is the first study on physician mental status during the Libya civil war. We enrolled $72 \%$ of potentially impacted emergency physicians to provide a snapshot of the current state of depression and anxiety disorders. Furthermore, we sought to highlight the physical and verbal abuses endured by doctors in Libya, who put their lives in danger during the local conflict. Although we excluded participants with any psychiatric illness or drug regimen for such disorders, the persistently higher rates of anxiety and depression among physicians working in emergency departments is an alarming sign. This signifies that early intervention in this area is required by the Libyan health authorities. However, a limitation of this study is its cross-sectional design; thus, we cannot establish causality with the risk factors that we studied. Due to the small sample size, there were some difficulties in assessing the direction of influence. In addition, we think that participants were afraid of being stigmatised for having a mental illness; thus, there was a high risk of interviewer bias, because some physicians may not have been willing to declare their mental status due to fear of potential professional discrimination and consequence on both short-term and long-term medical careers; ${ }^{22}$ previous studies have indicated that physicians fear such consequences. In one study, only $6 \%$ of physicians with mental illness had declared their condition to the licensing state. ${ }^{23}$ This reluctance to disclose mental illnesses and seek help may have negative consequences on the physicians' ability to work. The reluctance is mainly due to the fear of stigmatisation and the fear of losing license in future, and medical licensure application questions regarding mental health may be a barrier to disclosing the mental status of physicians. Therefore, there is a need for improved strategies to identify mental health issues and address physicians' concerns. ${ }^{24}$

Previous international studies have shown that medical doctors, regardless of their speciality, are at increased risk of depression compared with the general population. ${ }^{25}$ According to recent reports, this increase is associated with a higher risk of suicide, dropout and burnout 
among physicians. ${ }^{26}{ }^{27}$ Despite the utilisation of different methods to assess depression and anxiety, the estimated prevalence of depression among emergency physicians ranges from $10.7 \%$ to $47 \%$ based on several previous studies, which is in line with the findings of the present study. ${ }^{12} 132829$ Another prospective study conducted using the HADS inventory in Tunisian physicians from different specialities disclosed an anxiety prevalence of $43.6 \%$ and a depression prevalence of $30.5 \% .^{30}$ These findings are similar to our results, particularly given that Tunisia has a socioeconomic status similar to that of Libya. In addition, a study conducted in Saudi Arabia revealed mildto-moderate depression in $43.3 \%$ and $15.2 \%$ of resident physicians, respectively. ${ }^{31}$ Similar findings are present in other studies, such as from Malaysia, where 28.7\% of emergency physicians had anxiety and $10.7 \%$ had depression. ${ }^{12}$ Likewise, Erdur et al found that $15.1 \%$ of Turkish doctors had depression and $14.6 \%$ had anxiety disorders. ${ }^{13}$ Another study conducted among physiciansin-training in Nigeria revealed a depression prevalence of $17.3 \% .^{32}$ Interestingly, emergency physicians in Libya did not report substance use, although the literature supports the notion that emergency physicians usually have higher rates of substance misuse as a mechanism for coping stress or depression. ${ }^{33-35}$ Consistent with previous reports, the duration of work experience was not linked with the onset of depression or anxiety. ${ }^{36}$

Emergency doctors in Libya share the same risk factors for depression as doctors in other specialities. However, emergency physicians are at higher risk due to their job circumstances, patient population, working hours and the different types of stressors they face. ${ }^{26}{ }^{37}$ Among all medical specialities in the USA, emergency medicine has the highest burnout rate $(\sim 65 \%) .{ }^{38}{ }^{39}$ In addition to the aforementioned concerns, Libyan physicians experience specific constraints and difficulties due to the ongoing conflicts that have increased the risk of verbal and physical abuse by local militias. ${ }^{14}$ Civil war settings have increased the likelihood of verbal abuse and physical assaults, and emergency physicians risk being kidnapped or killed if they do not provide adequate care for militias' patients or their relatives. In addition, there have been several cases where doctors were threatened by weapons to treat patients or their friends, which therefore increased the stress endured by physicians working in the frontline of the civil war. These added factors correspond to higher levels of anxiety and depression in the emergency departments in Libya. The stressful conditions and financial crisis that occurred as a consequence of the civil wars may also contribute to these findings. ${ }^{40}$

Therefore, there is a need to address these concerns by local authorities by implementing strategies to support and protect physicians who are working in emergency departments, such as increasing legal enforcement and increasing security measures for the hospitals. Another protection strategy implies the policy of zero-tolerance toward violence in emergency departments. In addition, the local authorities should start mental health support programmes aiming to provide social and mental support, especially for those working during the civil war or near conflict zones. Although, these risk factors have been reported in previous studies, the risk of abuse was not reported in recent literature in conflict areas such as Libya. The heightened prevalence of depression and anxiety in Libyan emergency physicians should raise the alarm for relevant authorities and the Ministry of Health. This high prevalence can play a significant role in increasing the rate of medical errors, consequently affecting the quality of care provided to patients. ${ }^{271-43}$ The effects of anxiety and depression may persist for long periods of time, which can have negative effects on an individual's personal and social life. ${ }^{44-46}$ Moreover, high rates of depression and anxiety impair sleep quality, increase dropout rates, and contribute to suicide among physicians, all of which further exacerbate the problems faced when serving the Libyan population. ${ }^{5747} 48$ Additional research with more complex designs would help to determine the factors that lead to depression and anxiety. Furthermore, studies that focus on behaviour and reported abuse by militias are warranted, because their influence in the emergency departments are of major concern for doctors and staff that work in these stressful environments.

Libyan emergency physicians are at an increased risk of depression and anxiety due to the current civil war and financial crisis. In addition, they are at risk of physical and verbal abuse by militias. Therefore, there is an urgent need for action by authorities to provide mental health support, increase security measures to provide a safer working environment, and provide financial and social support for physicians during their work at the emergency department to ensure that physicians can provide adequate medical services for their patients, and to prevent the potentially catastrophic consequences of their mental health deterioration.

\section{Author affiliations}

${ }^{1}$ Faculty of Medicine, University of Tripoli, Tripoli, Libya

${ }^{2}$ Mitiga Hospital, Tripoli, Libya

${ }^{3}$ Tripoli University Hospital, Tripoili, Libya

${ }^{4}$ Ali Omar Askar-Neuro Hospital, Tripoli, Libya

${ }^{5}$ Misrata Medical Center, Tripoli, Libya

${ }^{6}$ Zawia Hospital, Tripoli, Libya

${ }^{7}$ Tripoli Central Hospital, Tripoli, Libya

${ }^{8}$ General Surgery, Alkhadra hospital, Tripoli, Libya

${ }^{9}$ Al Jala Hospital for Trauma and General Surgery, Benghazi, Libya

Twitter Muhammed Elhadi @ElhadiMuhammed, Hafed Abdulwahhab Albashkar @ Hafed and Aliyah Mustafa Alshareef @Aliyah-M-Alshareef

Contributors Conceptualisation: ME, AK, HA and ABM. Data curation: ME, ABM, AEA E-A, AZG, AZ, SME, AA, MAKAA, AA, HAA, AMA, ABBN and NAMS. Formal analysis: ME. Investigation: ME and HA. Writing - Original draft: ME, AK and HA. Writing Review and editing: $M E, A K, H A, A B M$ and $A Z$.

Funding The authors have not declared a specific grant for this research from any funding agency in the public, commercial or not-for-profit sectors.

Competing interests None declared.

Patient consent for publication Not required.

Ethics approval Ethical approval was obtained from the Bioethics Committee at Biotechnology Research Center of Ministry of Higher Education and Scientific Research in Libya (Reference number: BEC-BTC 6-2020). 
Provenance and peer review Not commissioned; externally peer reviewed.

Data availability statement Data are available upon reasonable request. De-identified participants data set is available by contacting Muhammed Elhadi, Muhammed.elhadi.uot@gmail.com.

Open access This is an open access article distributed in accordance with the Creative Commons Attribution Non Commercial (CC BY-NC 4.0) license, which permits others to distribute, remix, adapt, build upon this work non-commercially, and license their derivative works on different terms, provided the original work is properly cited, appropriate credit is given, any changes made indicated, and the use is non-commercial. See: http://creativecommons.org/licenses/by-nc/4.0/.

\section{ORCID iD}

Muhammed Elhadi http://orcid.org/0000-0001-6406-4212

\section{REFERENCES}

1 Schneider SE, Phillips WM. Depression and anxiety in medical, surgical, and pediatric interns. Psychol Rep 1993;72:1145-6.

2 Joules N, Williams DM, Thompson AW. Depression in resident physicians: a systematic review. OJD 2014;03:89-100.

3 Daw MA. Libyan healthcare system during the armed conflict: challenges and restoration. Afr J Emerg Med 2017;7:47-50.

4 Bragard I, Dupuis G, Fleet R. Quality of work life, burnout, and stress in emergency department physicians: a qualitative review. Eur $J$ Emerg Med 2015;22:227-34.

5 West CP, Tan AD, Habermann TM, et al. Association of resident fatigue and distress with perceived medical errors. JAMA 2009;302:1294-300.

6 de Jong MA, Nieuwenhuijsen K, Sluiter JK. Common mental disorders related to incidents and behaviour in physicians. Occup Med 2016;66:506-13.

7 West CP, Huschka MM, Novotny PJ, et al. Association of perceived medical errors with resident distress and empathy: a prospective longitudinal study. JAMA 2006;296:1071-8.

8 Yousuf A, Ishaque S, Qidwai W. Depression and its associated risk factors in medical and surgical post graduate trainees at a teaching hospital: a cross sectional survey from a developing country. J Pak Med Assoc 2011;61:968-73.

9 Sen S, Kranzler HR, Krystal JH, et al. A prospective cohort study investigating factors associated with depression during medical internship. Arch Gen Psychiatry 2010;67:557-65.

10 Hsu K, Marshall V. Prevalence of depression and distress in a large sample of Canadian residents, interns, and fellows. Am J Psychiatry 1987;144:1561-6.

11 Hsieh Y-H, Hsu C-Y, Liu C-Y, et al. The levels of stress and depression among interns and clerks in three medical centers in Taiwan--a crosssectional study. Chang Gung Med J 2011;34:278-85.

12 Yahaya SN, Wahab SFA, Yusoff MSB, et al. Prevalence and associated factors of stress, anxiety and depression among emergency medical officers in Malaysian hospitals. World J Emerg Med 2018;9:178-86.

13 Erdur B, Ergin A, Turkcuer I, et al. A study of depression and anxiety among doctors working in emergency units in Denizli, Turkey. Emerg Med J 2006;23:759-63.

14 Charlson FJ, Steel Z, Degenhardt L, et al. Predicting the impact of the 2011 conflict in Libya on population mental health: PTSD and depression prevalence and mental health service requirements. PLOS One 2012;7:e40593-e93.

15 Zeiton M. Frontline medicine: inside Libya. Lancet 2011;378:756-7.

16 Arie S. Agencies prepare to deal with mental health problems in Libya after 42 years of repression. BMJ 2011;343:d5653.

17 Steel Z, Chey T, Silove D, et al. Association of torture and other potentially traumatic events with mental health outcomes among populations exposed to mass conflict and displacement: a systematic review and meta-analysis. JAMA 2009;302:537-49.

18 Snaith RP, Zigmond AS. The hospital anxiety and depression scale. Br Med J 1986;292:344.

19 Bjelland I, Dahl AA, Haug TT, et al. The validity of the hospital anxiety and depression scale. An updated literature review. J Psychosom Res 2002;52:69-77.

20 Liang X, Guo Q, Luo J, et al. Anxiety and depression symptoms among caregivers of care-recipients with subjective cognitive decline and cognitive impairment. BMC Neurol 2016;16:191.
21 Stern AF. The hospital anxiety and depression scale. Occup Med 2014;64:393-4.

22 Swapnil S, Mehta BA, Matthew L, et al. Suffering in silence: mental health stigma and physicians' licensing fears. 2018;13:2-4.

23 Gold KJ, Andrew LB, Goldman EB, et al. "I would never want to have a mental health diagnosis on my record": A survey of female physicians on mental health diagnosis, treatment, and reporting. Gen Hosp Psychiatry 2016;43:51-7.

24 Wallace JE. Mental health and stigma in the medical profession. Health 2012;16:3-18.

25 Mata DA, Ramos MA, Bansal N, et al. Prevalence of depression and depressive symptoms among resident physicians: a systematic review and meta-analysis. JAMA 2015;314:2373-83.

26 Stehman CR, Testo Z, Gershaw RS, et al. Burnout, drop out, suicide: physician loss in emergency medicine, part I. West J Emerg Med 2019;20:485-94.

27 Pereira-Lima K, Mata DA, Loureiro SR, et al. Association between physician depressive symptoms and medical errors: a systematic review and meta-analysis. JAMA Netw Open 2019;2:e1916097.

28 Marchesi C, Brusamonti E, Borghi C, et al. Anxiety and depressive disorders in an emergency department ward of a general Hospital: a control study. Emerg Med J 2004;21:175-9.

29 Atif K, Khan HU, Ullah MZ, et al. Prevalence of anxiety and depression among doctors; the unscreened and undiagnosed clientele in Lahore, Pakistan. Pak J Med Sci 2016;32:294-8.

30 Marzouk M, Ouanes-Besbes L, Ouanes I, et al. Prevalence of anxiety and depressive symptoms among medical residents in Tunisia: a cross-sectional survey. BMJ Open 2018;8:e020655.

31 Al-Maddah EM, Al-Dabal BK, Khalil MS. Prevalence of sleep deprivation and relation with depressive symptoms among medical residents in King Fahd university Hospital, Saudi Arabia. Sultan Qaboos Univ Med J

32 Gu A, Onyeama G, Bakare M, et al. Prevalence of depression among resident doctors in a teaching Hospital, South East Nigeria. Int $J$ Psychiat Clin 2015;3:1-5.

33 Robinson GE. Stresses on women physicians: consequences and coping techniques. Depress Anxiety 2003;17:180-9.

34 Rose JS, Campbell M, Skipper G. Prognosis for emergency physician with substance abuse recovery: 5-year outcome study. West J Emerg Med 2014;15:20-5.

35 Hughes PH, Brandenburg N, Baldwin DC, et al. Prevalence of substance use among US physicians. JAMA 1992;267:2333-9.

36 Henning MA, Sollers J, Strom JM, et al. Junior doctors in their first year: mental health, quality of life, burnout and heart rate variability. Perspect Med Educ 2014;3:136-43.

37 Eckleberry-Hunt J, Lick D. Physician depression and suicide: a shared responsibility. Teach Learn Med 2015;27:341-5.

38 Goldberg R, Boss RW, Chan L, et al. Burnout and its correlates in emergency physicians: four years' experience with a wellness booth. Acad Emerg Med 1996;3:1156-64.

39 Shanafelt TD, Boone S, Tan L, et al. Burnout and satisfaction with work-life balance among US physicians relative to the general US population. Arch Intern Med 2012;172:1377-85.

40 Harchaoui J. Libya's monetary crisis. Lawfare, 2018.

41 Makary MA, Daniel M. Medical error-the third leading cause of death in the US. BMJ 2016;353:i2139.

42 Weingart SN, Wilson RM, Gibberd RW, et al. Epidemiology of medical error. BMJ 2000;320:774-7.

43 Jha AK, Larizgoitia I, Audera-Lopez C, et al. The global burden of unsafe medical care: Analytic modelling of observational studies. BMJ Qual Saf 2013:22:809-15.

44 Girard DE, Hickam DH, Gordon GH, et al. A prospective study of internal medicine residents' emotions and attitudes throughout their training. Acad Med 1991;66:111-4.

45 Choi D, Dickey J, Wessel K, et al. The impact of the implementation of work hour requirements on residents' career satisfaction, attitudes and emotions. BMC Med Educ 2006;6:53.

46 Girard DE, Hickam DH. Predictors of clinical performance among internal medicine residents. J Gen Intern Med 1991;6:150-4.

47 Fahrenkopf AM, Sectish TC, Barger LK, et al. Rates of medication errors among depressed and burnt out residents: prospective cohort study. BMJ 2008;336:488-91.

48 Khoushhal Z, Hussain MA, Greco E, et al. Prevalence and causes of attrition among surgical residents: a systematic review and metaanalysis. JAMA Surg 2017;152:265-72. 